\title{
Turner syndrome: don’t forget the vulva
}

\section{Dimitrios Haidopoulos, George Bakolas and Lina Michala}

Department of Obstetrics and Gynecology, Alexandra Hospital, University of Athens, 80 Vas Sofias Avenue, Athens, Greece

\section{Correspondence}

should be addressed

to L Michala

Email

linamichala@med.uoa.gr

\section{Summary}

Turner syndrome (TS) has been linked to a number of autoimmune conditions, including lichen sclerosus (LS), at an estimated prevalence of $17 \%$. LS is a known precursor to vulvar cancer. We present a case of vulvar cancer in a 44-year-old woman, who had previously complained of pruritus in the area, a known symptom of LS. Histology confirmed a squamous cell carcinoma with underlying LS. Vulvar assessment for the presence of LS should be undertaken regularly as part of the routine assessments proposed for adult TS women. If LS is identified, then the patient should be warned of the increased risk of vulvar cancer progression and should be monitored closely for signs of the condition.

\section{Learning points:}

- Patients with TS are at increased risk of developing LS.

- LS is a known precursor to vulvar cancer.

- TS women with LS may be at risk of developing vulvar cancer and should be offered annual vulvar screening and also be aware of signs and symptoms of early vulvar cancer.

\section{Background}

Turner syndrome (TS) appears to predispose to the development of vulvar lichen sclerosus (LS), a known precursor to vulvar cancer. Inspection of the vulva should be offered to all women with TS, irrespective of whether they are sexually active and, if diagnosed with LS, then an annual examination should be performed, to rule out development of vulvar cancer.

\section{Case presentation}

A 44-year-old woman with TS, non insulin-dependent diabetes melitus (NIDDM) and a history of ischemic heart disease was referred to our department for the management of vulvar cancer. She had a 45XO karyotype and was on continuous combined hormone replacement treatment since mid-puberty because of hypergonadotropic hypogonadism. The patient had reported vulvar itching for $\sim 1$ year prior to presentation.

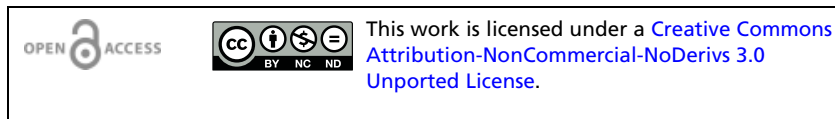

\section{Investigation}

At gynecological assessment, she was found to have a $2 \mathrm{~cm}$ lesion at the periclitoral area, for which she underwent a wide local excision. Histology confirmed a well-differentiated squamous cell vulvar carcinoma (SCC) with underlying LS. The depth of invasion was $1.5 \mathrm{~mm}$.

\section{Treatment}

Following diagnosis, the patient underwent a more radical excision and sentinel node sampling. Both samples were negative for disease.

\section{Outcome and follow up}

Six months after initial diagnosis, the patient remained disease free.

$\begin{array}{rr}\text { (C) } 2016 \text { The authors } & \text { http://www.edmcasereports.com } \\ \text { Published by Bioscientifica Ltd. }\end{array}$




\section{Discussion}

TS is one of the commonest chromosomal disorders in humans and is caused by the complete or partial absence of an X chromosome (1). TS is commonly diagnosed at birth or childhood due to related congenital anomalies and short stature. However, a proportion will be diagnosed later, at adolescence, due to delayed puberty and primary amenorrhea. Long-term follow up by a multidisciplinary team is required, due to multiple associated long-term health problems, such as cardiovascular disease, congenital or acquired, osteoporosis, recurrent ear infections and deafness (2). TS women are also more prone to developing autoimmune conditions such as Hashimoto's thyroiditis, IDDM, celiac disease and inflammatory bowel disease (3). The incidence of Hashimoto's thyroiditis is estimated at $50 \%$ in middle aged patients, (4) whereas the incidence of celiac disease is increased 11-fold (4). Autoimmune disorders become more prevalent as age advances. The exact pathophysiological mechanism remains unknown, but seems to involve disturbance in both humoral and cellular immune response (5). An increased frequency of LS has also been described at an estimate prevalence of $17 \%(6)$.

Although LS is known to predispose to vulvar cancer, this risk is rarely addressed as a possible concern in TS.

Interestingly, a number of case reports of vulvar cancer can be identified in the literature, which so far had not been linked to LS. The first reported case was in a 41-year-old single nulliparous woman, whose histology was negative for human papillomavirus (HPV) (7). The second case was of a 35-year-old with TS, again unlikely to have contracted HPV, as she was not known to be sexually active (8). There is a third reported case in the literature of a 61-year-old with no mention of sexual history or underlying HPV infection (9).

LS is a skin condition, probably of autoimmune aetiology, although infections, hormonal and genetic factors have been incriminated (5). LS affects women of all ages with an increased incidence in the menopause (10). There are typical white atrophic papules that may unite into porcelain-white plaques, leading to thin and crinkled skin that distort normal external genitalia anatomy. Genital skin, including skin over the mons pubis and perineum is often involved, giving a typical figure of eight or hourglass pattern. Skin changes occur only externally and the vagina is not affected. When LS remains untreated, labia minora gradually atrophy, labia majora become flat, adhesions or strictures can form at the introitus or around the prepuce, leading to a hooded clitoris. Common symptoms may be pruritus or skin irritation.
Labial adhesions can form, leading to urinary problems, and fissures and skin splitting often lead to sexual difficulties and superficial dyspareunia (11). LS often remains underdiagnosed, usually because the patient shies away from medical attention, but also as the condition may not be readily identified by general physicians or endocrinologists.

The risk of developing vulvar cancer in women with LS is estimated at $\sim 3-7 \%$ (12), whereas two-thirds of vulvar cancer cases arise in close proximity to LS (13). The link is strong enough to make LS a precursor of invasive squamous cell vulvar cancer. The usual recommendation is that patients diagnosed with LS should have an annual vulvar assessment to rule out the presence of cancer. They are also advised to notify their physician if they identify a suspicious lesion in the area (14).

Vulvar cancers are uncommon and represent $\sim 5 \%$ of all gynecologic malignancies (10). Most of them are diagnosed at an early stage-although advanced disease is common in older women due to delayed presentation. Approximately $90 \%$ are SCCs (10). Early detection by biopsy of any abnormal lesions is important for early diagnosis, which will improve morbidity and mortality.

A recent epidemiological study from the UK suggests a decreasing trend of vulvar SCC in older women, attributed to a better surveillance of precancerous conditions such as LS and lichen planus. Contrarily more patients are now diagnosed at a younger age, plausibly as a result of increasing HPV infection prevalence (15).

This present case stresses the importance of awareness and monitoring of the vulva in TS patients so as to identify LS, a potential precursor of vulvar cancer.

\section{Declaration of interest \\ The authors declare that there is no conflict of interest that could be perceived as prejudicing the impartiality of the research reported.}

\section{Funding}

This research did not receive any specific grant from any funding agency in the public, commercial or not-for-profit sector.

\section{Patient consent}

Written informed consent has been obtained from the patient for publication of this case report.

Author contribution statement

D Haidopoulos was the physician of the patient and wrote the paper. $\mathrm{G}$ Bakolas helped draft the paper. L Michala wrote and reviewed the paper. 


\section{References}

1 Tesch LG, Rosenfeld RC \& Henry H 1995 Turner 1892-1970 morgagni, ullrich and turner: the discovery of gonadal dysgenesis. Endocrinologist 5 327-328. (doi:10.1097/00019616-199509000-00002)

2 Conway GS, Band M, Doyle M \& Davies MC 2010 How do you monitor the patient with Turner's syndrome in adulthood. Clinical Endocrinology 73 696-699. (doi:10.1111/j.1365-2265.2010.03861.x)

3 Goldacre MJ \& Seminog O 2014 Turner syndrome and autoimmune diseases: record-linkage study. Archives of Disease in Childhood 99 71-73. (doi:10.1136/archdischild-2013-304617)

4 Mortensen KH, Cleemann L, Hjerrild BE, Nexo E, Locht H, Jeppesen EM \& Gravholt CH 2009 Increased prevalence of autoimmunity in Turner syndrome - influence of age. Clinical and Experimental Immunology 156 205-210. (doi:10.1111/j.1365-2249.2009.03895.x)

5 Smith YR \& Haefner HK 2004 Vulvar lichen sclerosus: pathophysiology and treatment. American Journal of Clinical Dermatology 5 105-125. (doi:10.2165/00128071-200405020-00005)

6 Chakhtoura Z, Vigoureux S, Courtillot C, Tejedor I \& Touraine P 2014 Image in endocrinology: vulvar lichen sclerosus is very frequent in women with Turner's syndrome. Journal of Clinical Endocrinology and Metabolism 99 1103-1104. (doi:10.1210/jc.2013-3480)

7 Iwamoto I, Kijima Y, Fujino T, Yoshinaga M \& Douchi T 2004 Verrucous carcinoma of the vulva in Turner syndrome. Gynecologic Oncology 92 380-383. (doi:10.1016/j.ygyno.2003.10.009)

8 Tapisiz OL, Topcu O, Gungor T, Ozdal B, Sirvan L \& Yesilyurt A 2011 Squamous cell carcinoma of the vulva in a virgin patient with Turner syndrome. Journal of Gynecologic Oncology 22 211-213. (doi:10.3802/ jgo.2011.22.3.211)

9 Al Inizi S \& Keating P 2006 Squamous cell carcinoma of the vulva in Turner syndrome. Internet Journal of Gynecology and Obstetrics 7. (http://ispub.com/IJGO/7/1/3989)

10 Henquet CJ 2011 Anogenital malignancies and pre-malignancies. Journal of the European Academy of Dermatology and Venereology $\mathbf{2 5}$ 885-895. (doi:10.1111/j.1468-3083.2010.03969.x)

11 van de Nieuwenhof HP, van der Avoort IA \& de Hullu JA 2008 Review of squamous premalignant vulvar lesions. Critical Reviews in Oncology/Hematology 68 131-156. (doi:10.1016/j.critrevonc.2008. 02.012)

12 Pugliese JM, Morey AF \& Peterson AC 2007 Lichen sclerosus: review of the literature and current recommendations for management. Journal of Urology 178 2268-2276. (doi:10.1016/j.juro.2007. 08.024)

13 Leibowitch M, Neill S, Pelisse M \& Moyal-Baracco M 1990 The epithelial changes associated with squamous cellcarcinoma of the vulva: a review of the clinical, histological and viral findings in 78 women. British Journal of Obstetrics and Gynaecology 97 1135-1139. (doi:10.1111/j. 1471-0528.1990.tb02502.x)

14 Neil SM, Lewis FM, Tatnall FM \& Cox NH 2010 British Association of Dermatologists' guidelines for the management of Lichen sclerosus 2010. British Journal of Dermatology 147 640-9. (doi:10.1046/j.13652133.2002.05012.x)

15 Lai J, Elleray R, Nordin A, Hirschowitz L, Rous B, Gildea C \& Poole J 2014 Vulval cancer incidence, mortality and survival in England: age-related trends. BJOG 121 728-738. (doi:10.1111/1471-0528.12459)

Received in final form 17 January 2016

Accepted 29 March 2016 